\title{
Article \\ Association of TaD14-4D, a Gene Involved in Strigolactone Signaling, with Yield Contributing Traits in Wheat
}

\author{
Ruifang Liu ${ }^{1,2,3,4}$, Jian Hou ${ }^{4}$, Huifang $\mathrm{Li}^{4}$, Ping Xu ${ }^{1,2,3}$, Zhengbin Zhang ${ }^{1,2,3, *(1)}$ and Xueyong Zhang ${ }^{4, *}$ \\ 1 Key Laboratory of Agricultural Water Resources, Hebei Laboratory of Agricultural Water-Saving, \\ Center for Agricultural Resources Research, Institute of Genetics and Developmental Biology, \\ Chinese Academy of Sciences, Shijiazhuang 050022, China; lrf0720@163.com (R.L.); \\ xuping@sjziam.ac.cn (P.X.) \\ 2 College of Advanced Agricultural Sciences, University of Chinese Academy of Sciences, Beijing 100049, China \\ 3 Innovation Academy for Seed Design, Chinese Academy of Sciences, Beijing 100101, China \\ 4 Key Laboratory of Crop Gene Resources and Germplasm Enhancement, Institute of Crop Science, \\ Chinese Academy of Agricultural Sciences, Beijing 100081, China; houjian@caas.cn (J.H.); \\ lihuifang0213@163.com (H.L.) \\ * Correspondence: zzb@sjziam.ac.cn (Z.Z.); zhangxueyong@caas.cn (X.Z.)
}

Citation: Liu, R.; Hou, J.; Li, H.; Xu, P.; Zhang, Z.; Zhang, X. Association of TaD14-4D, a Gene Involved in Strigolactone Signaling, with Yield Contributing Traits in Wheat. Int. J. Mol. Sci. 2021, 22, 3748. https:// doi.org/10.3390/ijms22073748

Academic Editor: Setsuko Komatsu

Received: 3 March 2021

Accepted: 1 April 2021

Published: 3 April 2021

Publisher's Note: MDPI stays neutral with regard to jurisdictional claims in published maps and institutional affiliations.

Copyright: (c) 2021 by the authors. Licensee MDPI, Basel, Switzerland. This article is an open access article distributed under the terms and conditions of the Creative Commons Attribution (CC BY) license (https:// creativecommons.org/licenses/by/ $4.0 /)$.

\begin{abstract}
Tillering is a crucial agronomic trait of wheat; it determines yield and plant architecture. Strigolactones (SLs) have been reported to inhibit plant branching. D14, a receptor of SLs, has been described to affect tillering in rice, yet it has seldomly been studied in wheat. In this study, three TaD14 homoeologous genes, TaD14-4A, TaD14-4B, and TaD14-4D, were identified. TaD14-4A, $T a D 14-4 B$, and $T a D 14-4 D$ were constitutively expressed, and TaD14-4D had a higher expression level in most tissues. TaD14 proteins were localized in both cytoplasm and nucleus. An SNP and a $22 \mathrm{bp}$ insertion/deletion (Indel) at the exon regions of TaD14-4D were detected, forming three haplotypes, namely $4 \mathrm{D}$-HapI, $4 \mathrm{D}$-HapII, and $4 \mathrm{D}$-HapIII. Due to the frameshift mutation in the coding region of 4D-HapII, the interaction of 4D-HapII with TaMAX2 and TaD53 was blocked, which led to the blocking of SL signal transduction. Based on the two variation sites, two molecular markers, namely $d C A P S-250$ and Indel-747, were developed. Association analysis suggested that haplotypes of TaD14-4D were associated with effective tillering number (ETN) and thousand kernel weight (TKW) simultaneously in four environments. The favorable haplotype $4 \mathrm{D}$-HapIII underwent positive selection in global wheat breeding. This study provides insights into understanding the function of natural variations of TaD14-4D and develops two useful molecular markers for wheat breeding.
\end{abstract}

Keywords: TaD14; strigolactone signaling; haplotype; effective tillering number; thousand kernel weight; molecular marker; wheat

\section{Introduction}

Plant architecture, an important index determined in great part by shoot branching (tillering in crops), is one of the key factors of the yield component [1]. Shoot branching is under integrated regulation by hormonal, developmental, and environmental factors [2,3]. Strigolactones (SLs) are a group of carotenoid-derived plant hormones, which were demonstrated for the first time in 2008 as regulators that can inhibit the outgrowth of axillary buds, whose function is highly conserved in both monocots and dicots [4,5]. Other functions have been proposed for SLs in the regulation of plant growth and development, including accelerating leaf senescence [6,7], promoting secondary growth of stems [8], regulating plant root development [9], mediating plant tolerance to nutrient deficiency [10], and enhancing plant response to drought and high salt stress [11,12].

The biosynthesis of SLs begins from $\beta$-carotene. D27/AtD27 encodes a $\beta$-carotene isomerase, which converts all-trans- $\beta$-carotene to 9 -cis- $\beta$-carotene in the initial steps [13-15]. Then, the catalysis of carotenoid cleavage dioxygenase 7 (CCD7) and CCD8 (encoded by 
HTD1/D17/MAX3 [16-18] and D10/MAX4 [19] in rice (Oryza sativa) and Arabidopsis (Arabidopsis thaliana), respectively) produces carlactone (CL) [13], the last common precursor for all SLs [20]. Recent studies have shown that MAX1 and other enzymes can catalyze the biosynthesis of both canonical and noncanonical SLs from CL, whereas this process is different in rice and Arabidopsis [21-23].

Studies on a series of SL-insensitive mutants indicated that the SLs signaling mechanism involves targeted degradation of hormone-activated proteins, similar to auxin, jasmonic acid (JA), and gibberellic acid (GA) [20,24]. The perception and signal transduction of SLs in rice and Arabidopsis are coordinated by three highly conserved components [25]: DWARF14 (D14)/AtD14 [26,27], D3/MAX2 [28-30], and D53/SMXL6/7/8 [3,31,32]. D14, an $\alpha / \beta$-hydrolase protein with a strictly conserved Ser-His-Asp catalytic triad, has been identified as an SL receptor [33-35]. Compared with other plant hormone receptors, D14 is unique in that it is a novel type of hormone receptor with dual functions of enzyme and receptor [36]. D3/MAX2 encodes an F-box protein with a leucine-rich repeat (LRR) sequence, which is involved in the formation of the SCF protein complex [25,28]. In 2013, there was a significant breakthrough in the study of SL signaling transduction. D53, a repressor of SL signaling, was identified as a substrate of the $\mathrm{SCF}^{\mathrm{D} 3}$ ubiquitination complex $[3,31]$.

Wheat is one of the most important staple crops in the world. It is estimated that by 2050 , wheat production needs to be increased by $70 \%$ from the current level in order to meet the needs of the growing world population [37]. Tillering is a crucial agronomic trait of wheat; it determines yield and plant architecture [38]. The proper number of tillers is of great significance to wheat production. The functions of SLs as plant hormones mainly affect plant branches $[4,5]$. However, to date, few studies on the genes involved in SL biosynthesis and signal transduction have been reported in wheat, and the roles of these genes in influencing wheat tillering and other agronomic traits remain unclear.

Association analysis based on gene polymorphism has been proved to be an effective method to reveal the relationship between genes and traits and has been widely performed in many plant species, such as for OsLG3b in rice [39], ZmVPP1 in maize [40], and TaDA1 [41] and TaBT1 [42] in wheat. A series of key haplotypes that can be distinguished by effective molecular markers and which are associated with important traits have been identified using this method [43]. Moreover, the use of marker-assisted selection (MAS) to accumulate favorable alleles or haplotypes is considered a potential way to accelerate the process of wheat breeding [44]. Hence, the discovery of excellent gene allelic variations and the development of molecular markers have practical value for the breeding and genetic improvement of wheat.

In this study, the major objectives were to (1) isolate and characterize three homeologs of TaD14 from wheat, (2) explore expression patterns of TaD14 genes in various tissues and periods, (3) identify sequence diversity and elucidate the possible molecular mechanism of a natural mutation of TaD14-4D, (4) develop functional markers to distinguish haplotypes and associate them with agronomic traits, and (5) evaluate the value of the newly developed molecular markers and assess whether different haplotypes were selected by analyzing the geographic distribution and frequency of favorable allelic variation. This study aimed to identify potentially important genes and provide a valuable functional marker for molecular marker-assisted wheat breeding.

\section{Results}

\subsection{Identification and Structural Analysis of TaD14 Genes}

Dwarf 14 (D14) encodes an $\alpha / \beta$-fold hydrolase superfamily protein. Loss of function mutants exhibit dwarf and high tillering phenotype in rice [26]. To investigate the function of D14 in wheat, the coding sequence (CDS) of OsD14 (Os03g0203200) was used as a query to search in the Chinese Spring RefSeq v1.0 genome database [45]. Three D14 homeologs located in chromosomes 4AS (TraesCS4A02G046700), 4BL (TraesCS4B02G258200), and 4DL (TraesCS4D02G258000) were obtained and named TaD14-4A, TaD14-4B, and TaD14-4D. Primers were designed based on specific regions for each sequence (Table S1) to clone the 
genomic sequence and CDS of TaD14 genes using genomic DNA and cDNA samples of Chinese Spring. All three homoeologous genes of TaD14 were composed of two exons and one intron (Figure 1A). The genomic sequence lengths of TaD14-4A, TaD14-4B, and TaD14- $4 \mathrm{D}$ were 1013,1039 , and $1027 \mathrm{bp}$, respectively, encoding putative products of 302, 297, and 300 amino acids, respectively (Figure S1). In addition, these proteins had a high identity of $98.01 \%$ and all contained an $\alpha / \beta$-hydrolase fold domain (Figure 1B), indicating that they could perform a similar function in wheat.

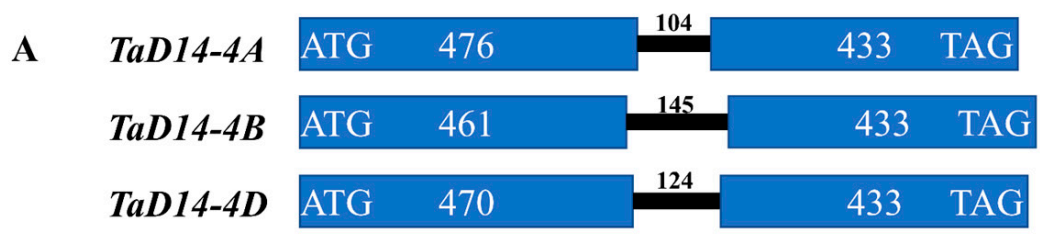

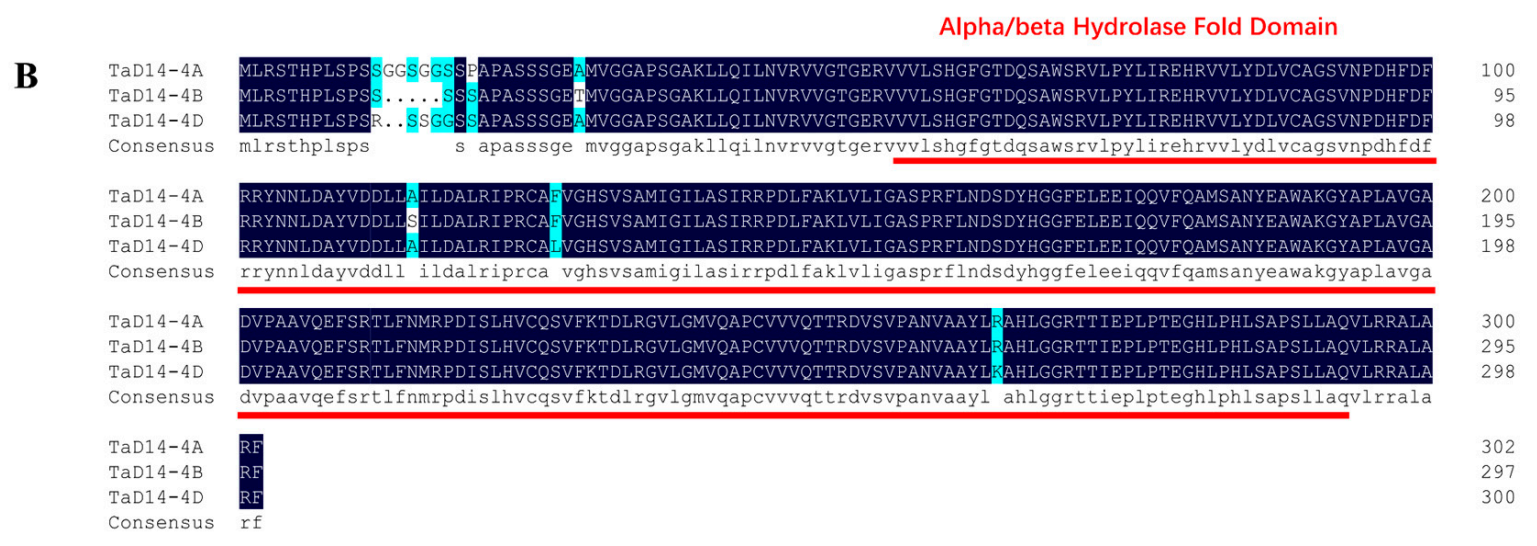

Figure 1. Structures of TaD14 homoeologous genes and amino acid sequence alignment. (A) Gene structures of TaD14-4A, TaD14-4B, and TaD14-4D. The blue rectangles represent exons, the solid black line between exons represents introns, and the number above represents the number of bases. (B) The amino acid sequence alignment of TaD14 proteins in Chinese Spring. The predicted $\alpha / \beta$-hydrolase fold domain is indicated by the red line.

The phylogenetic analysis revealed that the TaD14 protein had the closest homology relationship with D14 of Triticum turgidum, Aegilops tauschii, Hordeum vulgare, Brachypodium distachyon, and Oryza sativa subsp. Japonica (Figure 2A). Interestingly, except for four cruciferous plants, the D14 genes of the other species all contained two exons and one intron (Figure 2B), indicating that they were highly conserved in both dicots and monocots during the evolutionary process.

\subsection{Expression Patterns of TaD14 Genes and Subcellular Localization of TaD14 Proteins}

qRT-PCR was performed to explore expression patterns of TaD14 genes using genomespecific primers (Table $\mathrm{S} 1$ ) so as to clarify the expression of TaD14 genes in different tissues and growth periods of wheat and to better grasp its dynamic patterns. The expression patterns of TaD14 genes were similar. They were ubiquitously expressed in all the detected tissues at different stages. The expression levels of $T a D 14$ genes in leaves were significantly higher than those in other organs, followed by the expression levels in roots. In general, the expression levels of $T a D 14-4 B$ and $T a D 14-4 D$ in all the detected tissues were significantly higher than those of TaD14-4A (Figure 3A). 
A

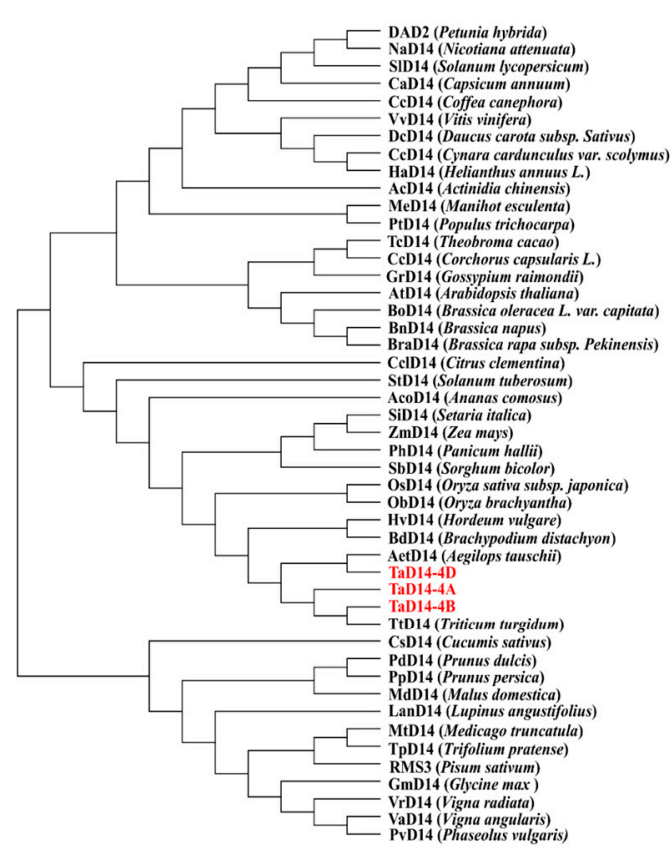

B

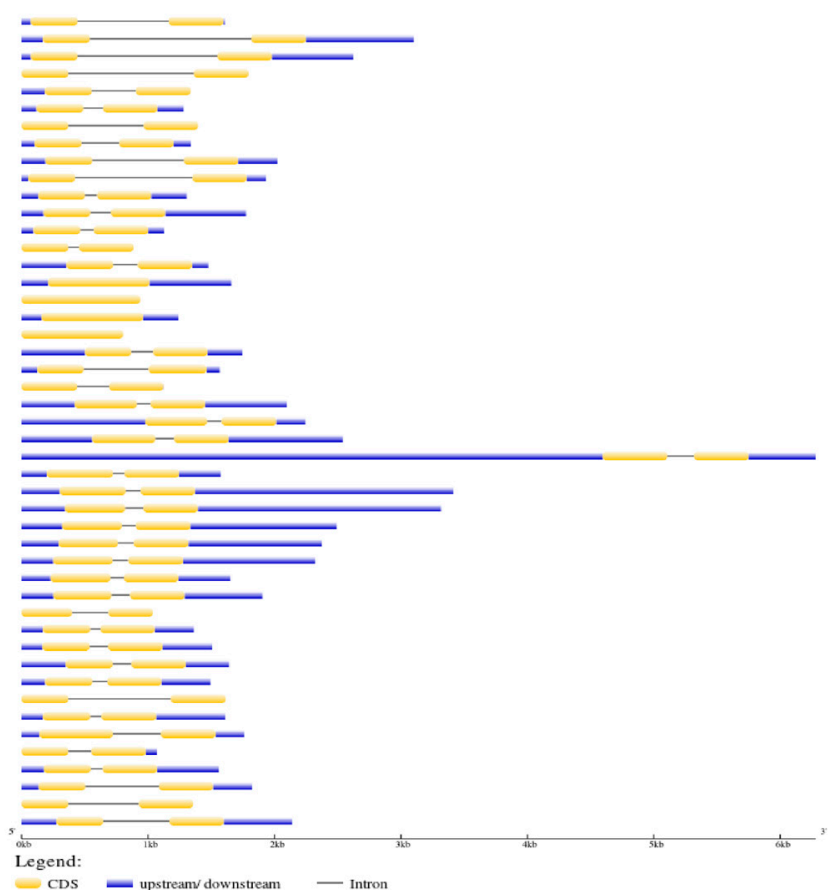

Figure 2. Phylogenetic relationships of D14 proteins in different species and the corresponding D14 gene structures. (A) Phylogenetic tree constructed from the D14 protein sequences of 47 different species using the neighbor-joining method with a bootstrap value of 1000 by MEGA7.0. Three homoeologous proteins of TaD14 are marked in red. (B) Gene structures of $D 14$. The yellow boxes indicate coding sequences, the blue boxes represent the untranslated regions, and the black lines represent introns. The length of coding sequence (CDS) and introns can be estimated using the scale at the bottom.

A

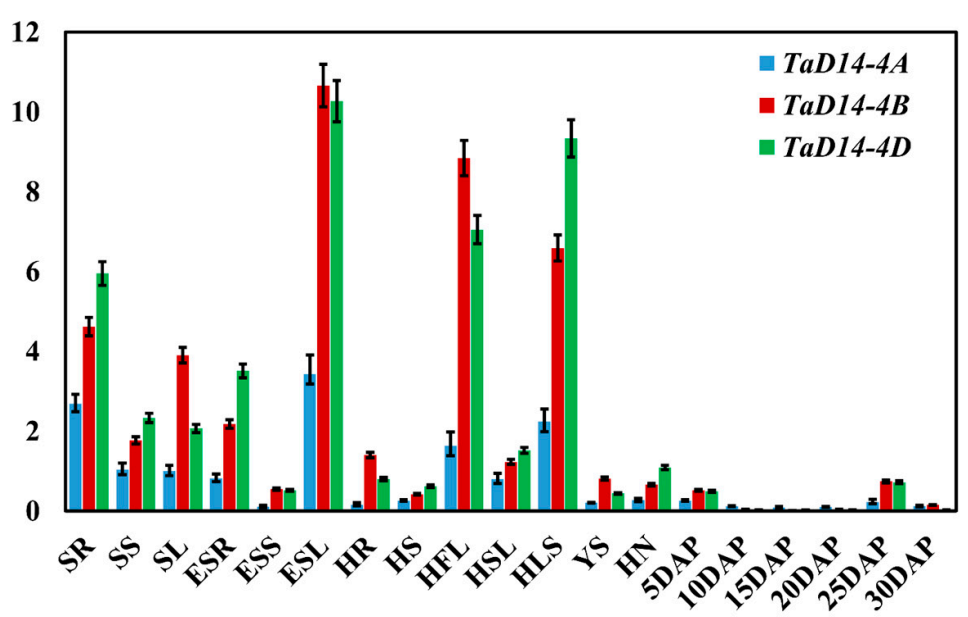

B

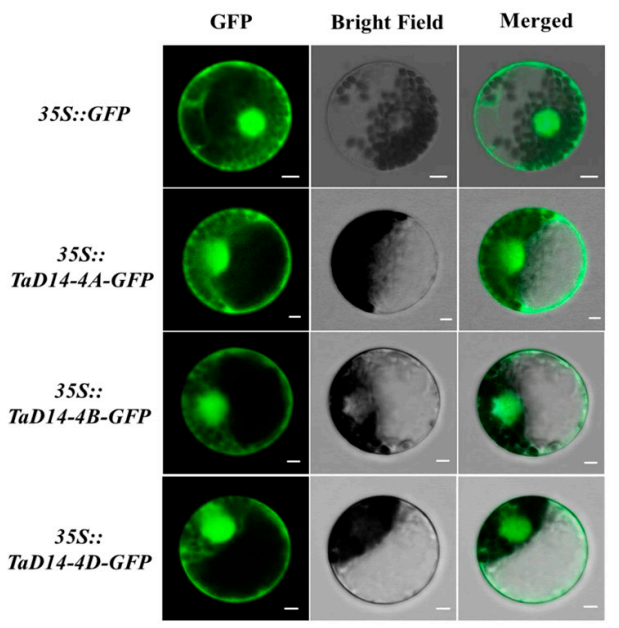

Figure 3. Expression analyses of TaD14 genes and subcellular localization of TaD14 proteins. (A) Tissue-specific expression pattern of TaD14 genes in different tissues and growth periods of Chinese Spring. SR, seedling roots; SS, seedling stems; SL, seedling leaves; ESR, roots at elongation stage; ESS, stems at elongation stage; ESL, leaves at elongation stage; HR, roots at heading stage; HS, stems at heading stage; HFL, flag leaves at heading stage; HSL, top second leaves at heading stage; HLS, leaf sheaths at heading stage; YS, young spikes; HN, nodes at heading stage; DAP, days after pollination, grains at different developmental stages, namely 5, 10, 15, 20, 25, and 30 DAP. The normalized value of TaD14 gene expression relative to TaActin is derived from the mean \pm SD of three technical repeated experiments. (B) Subcellular localization of TaD14 proteins in wheat leaf protoplasts. The free GFP and TaD14-GFP fusions under the control of the cauliflower mosaic virus $35 \mathrm{~S}$ promoter were transiently expressed in wheat leaf protoplasts. The fluorescence signal of GFP was observed under a confocal laser scanning microscope after transfection for $16 \mathrm{~h}$. Scale bars, $10 \mu \mathrm{m}$. 
To examine the subcellular localization of TaD14 proteins, we transiently expressed the $p 35 S-T a D 14-G F P$ (green fluorescent protein) fusion construct in wheat leaf protoplasts. After overnight incubation $(16 \mathrm{~h})$, the protoplasts were analyzed using a confocal microscope. As shown in Figure 3B, TaD14-GFP constructs were localized in both cytoplasm and nucleus, which was consistent with the localization of D14 in Arabidopsis and rice [27,46].

\subsection{Variations of TaD14-4D among Wheat Accessions}

Since the identity of TaD14 homoeologs was extremely high and TaD14-4D had a higher expression level in most tissues, we speculated that it may have a greater impact on related agronomic traits. To clarify nucleotide natural polymorphisms in TaD14-4D, we detected its natural variations in the coding and promoter regions of TaD14- $4 \mathrm{D}$ in 32 wheat accessions (Table S2) with high genetic diversities. No mutation site was present in the promoter region, yet a single nucleotide polymorphism (SNP) in the first exon and a $22 \mathrm{bp}$ insertion/deletion (Indel) in the second exon were detected, which constituted three haplotypes, 4D-HapI, 4D-HapII, and 4D-HapIII (Figure 4).

\section{A}

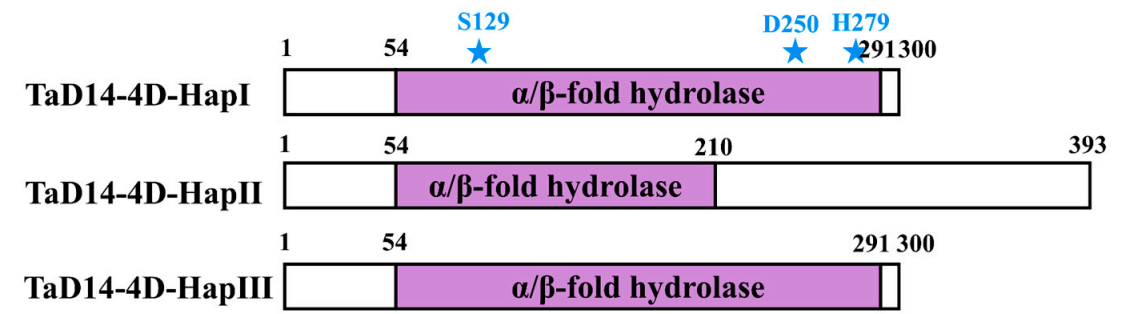

B

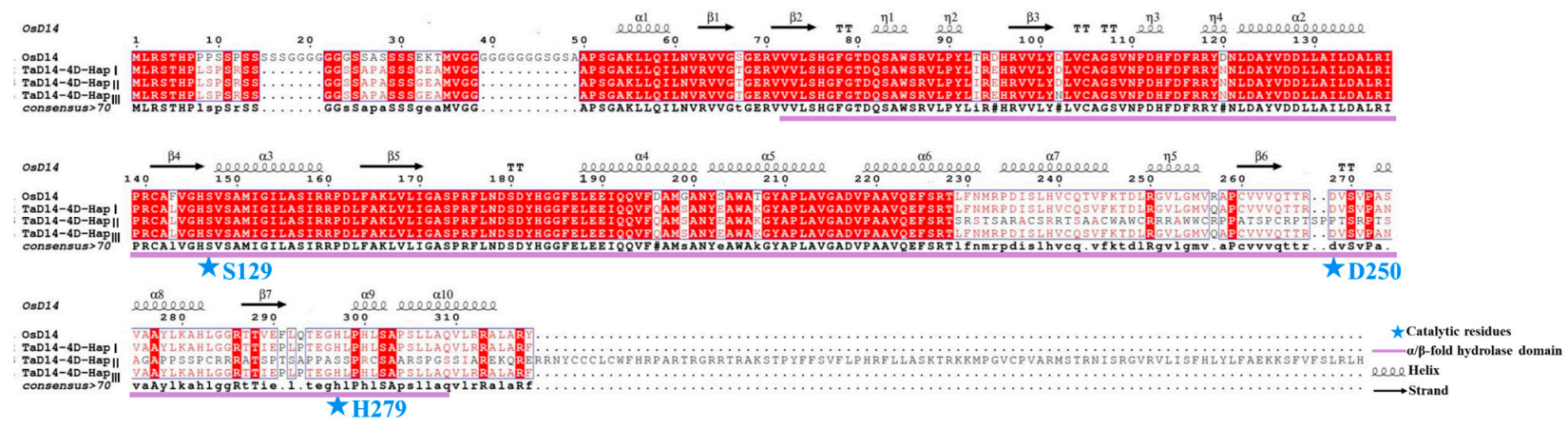

Figure 4. Comparison of protein structures in different haplotypes of TaD14-4D. (A) Protein structure in different TaD14-4D haplotypes. The purple boxes represent $\alpha / \beta$-hydrolase fold domain and the number above represents the number of amino acids. (B) Sequence alignment and structural annotation of TaD14-4D among different haplotypes. Identical and similar residues are highlighted in red and white backgrounds, respectively. The three catalytic residues represented by blue stars, S129, D250, and H279, were deduced from OsD14. The secondary structure of OsD14 was from Nakamura et al. [33]. The purple line indicates $\alpha / \beta$-hydrolase fold domain.

The SNP at position 250 in the first exon of 4 D-HapIII led to an amino acid change $(\mathrm{GAC} \rightarrow \mathrm{AAC}, \mathrm{Asp} \rightarrow \mathrm{Asn})$. The $22 \mathrm{bp}$ Indel in the coding region of $4 \mathrm{D}$-HapII caused frameshift mutations, which added 93 extra amino acids (Figure 4). The $\alpha / \beta$-hydrolase fold domain of 4D-HapII was destroyed, which led to the abnormal catalytic triad composed of the Ser-His-Asp that recognizes and hydrolyzes SLs (Figure 4A). When comparing the amino acid sequences of the three haplotypes (Figure 4B) with the secondary structure of OsD14 [33], the alignment suggests that the mutation sites of 4D-HapII cause large changes in the secondary structure, which may lead to changes in function.

\subsection{The SL Signaling Pathway Is Blocked in 4D-HapII}

In order to explore the functional defect of D14 in 4D-HapII, subcellular localization of the $4 \mathrm{D}-\mathrm{HapII}$ was investigated first. The 4D-HapII and TaD14 had the same subcellular 
localization pattern, both localized in cytoplasm and nucleus (Figures S2 and Figure 3B), which indicates that frameshift mutations did not disturb localization. In rice, OsD14 could perceive SL signal and form a complex with signaling pathway molecules OsD3 and OsD53 to mediate SL signal transduction as a bifunctional protein [3,31]. The subcellular localization patterns of TaMAX2 and TaD53 (ortholog of OsD3 and OsD53 in wheat), two other members of the SL signaling pathway in wheat, were both localized in the nucleus (Figure S2). The subcellular localization of GFP-4D-HapII overlapped with TaMAX2 and TaD53. Therefore, we investigated whether 4D-HapII could interact with them.

To test the interaction of $4 \mathrm{D}$-HapII with TaMAX2, a firefly luciferase complementation imaging (LCI) assay was employed in tobacco (Nicotiana benthamiana) leaves. As shown in Figure 5A, TaD14-4D directly interacted with TaMAX2, while 4D-HapII could not interact. We further investigated the interaction using the bimolecular fluorescence complementation (BiFC) assays. For this experiment, TaD14-4D and 4D-HapII were fused with the split amino-terminus of yellow fluorescent protein (YFP) protein and TaMAX2 was fused with the split carboxy-terminus of YFP protein to generate nYFP-TaD14-4D, nYFP-4D-HapII, and CYFP-TaMAX2. Consistently, BiFC assays also demonstrated that TaD14-4D could directly interact with TaMAX2 in the nucleus, while 4D-HapII could not (Figure 5B).

A

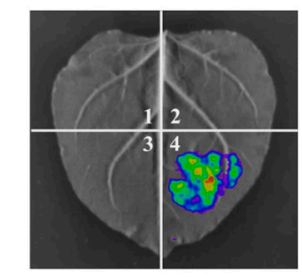

$$
\text { 1.nLUC + cLUC }
$$
2.nLUC-TaD14-4D + cLUC 3.nLUC + cLUC-TaMAX2
4.nLUC-TaD14-4D+ cLUC-TaMAX2
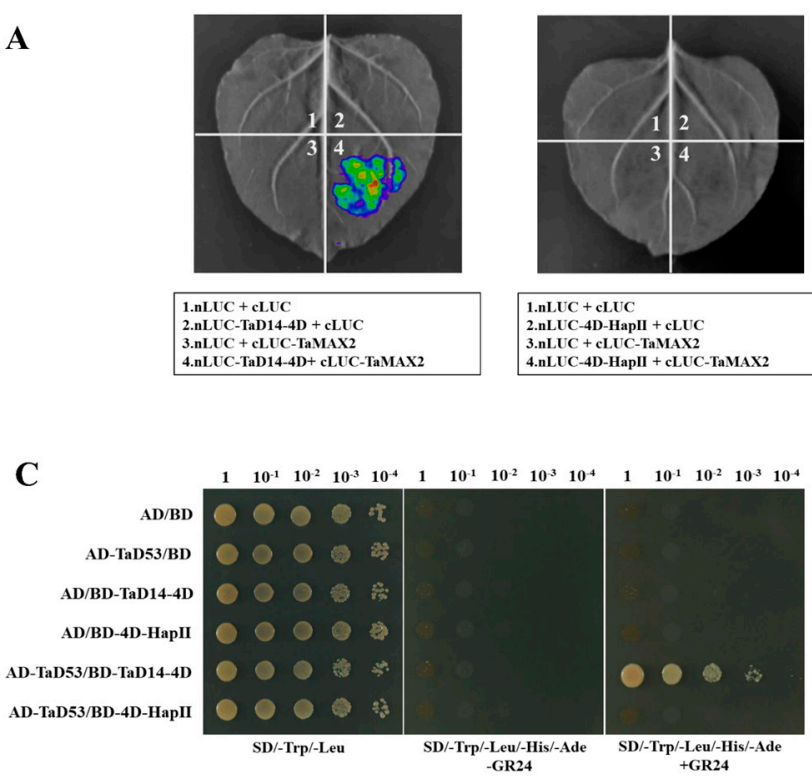

B

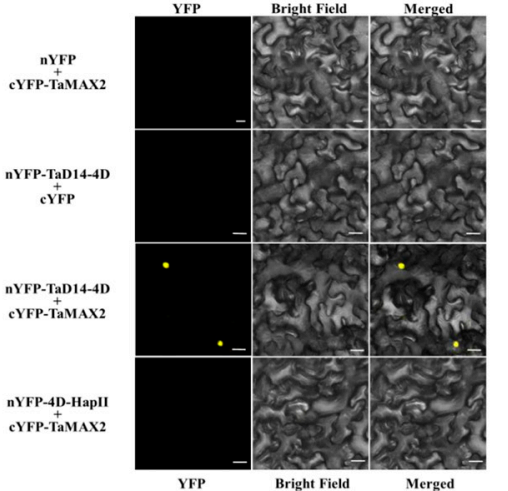

D

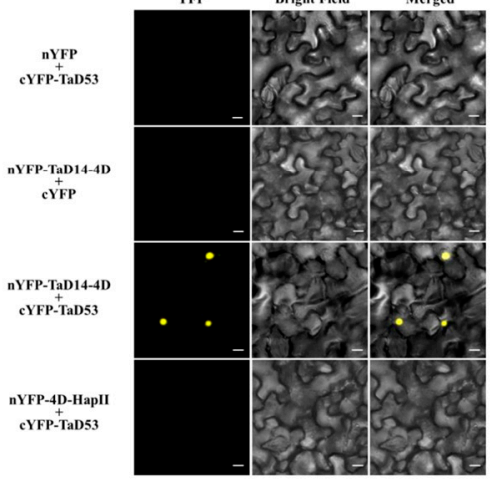

Figure 5. The interactions between TaD14-4D haplotypes and strigolactone pathway members TaMAX2 and TaD53. (A) LCI assay showed TaMAX2 interacts with TaD14-4D instead of 4D-HapII. nLUC, N-terminal of LUC; cLUC, C-terminal of LUC. (B) BiFC assay showed TaMAX2 interacts with TaD14-4D instead of 4D-HapII. YFP, yellow fluorescent protein. nYFP and cYFP represent the N-terminal and C-terminal of YFP, respectively. BF, bright-field. Scale bars, $20 \mu \mathrm{m}$. (C) Yeast two-hybrid assay showed TaD53 interacts with TaD14-4D instead of 4D-HapII. AD, activating domain; BD, binding domain; $\mathrm{SD}$, synthetic dropout medium. Yeast transformants were spotted on the control medium (SD/Trp/Leu, SD lacking Trp and Leu) and selective medium (SD/Trp/Leu/His/Ade, SD lacking Trp, Leu, His, and Ade). The yeast transformants were 10-fold serially diluted and spotted onto the selected medium. (D) BiFC assay showed TaD53 interacts with TaD14-4D instead of 4D-HapII. Scale bars, $20 \mu \mathrm{m}$. Three independent tobacco leaves were used for LUC and YFP signal detection.

A yeast two-hybrid ( $\mathrm{Y} 2 \mathrm{H})$ assay was set up to detect the differences in TaD14-4D and 4D-HapII interaction with TaD53. The results suggested that neither TaD14-4D nor 4D-HapII could physically interact with TaD53 in the absence of GR24, an artificial SL 
analog (Figure 5C). When the final concentration of $5 \mu \mathrm{m}$ GR24 was added to the yeast selective medium, TaD14-4D could interact with TaD53 protein in the presence of GR24, but 4D-HapII could not (Figure 5C). Simultaneously, BiFC assays also confirmed that 4D-HapII could not interact with TaD53 (Figure 5D). The above results indicate that the MAX2-D14-D53 protein complex with D14 as the center could not form in 4D-HapII. As a consequence, the ubiquitin ligase TaMAX2 was unable to physically approach the substrate TaD53, resulting in blocked SL signaling transduction.

\subsection{Molecular Marker Development of TaD14-4D Haplotypes and Association Analysis with Agronomic Traits}

Based on the polymorphic sites, two molecular markers were developed to distinguish the three haplotypes, named dCAPS-250 and Indel-747. Based on the SNP(G/A) at base pair 250 (Figure 6A), a derived cleaved amplified polymorphic sequence (dCAPS) marker was developed to distinguish 4D-HapIII from 4D-HapI and 4D-HapII (Figure 6B). The marker contained two mismatches in the downstream primer that produced a recognition site for the restriction enzyme EcoRI at 4D-HapI and 4D-HapII, but not at 4D-HapIII (Figure 6B, Table S1). After two-step PCR amplification and enzyme digestion, the amplified fragments of $4 \mathrm{D}$-HapIII could be separated (Figure 6B). The Indel marker was developed based on a deletion of $22 \mathrm{bp}$ at base pair 747 to discriminate $4 \mathrm{D}$-HapII (Figure 6C). After two-step amplification, the PCR products could be distinguished by $4 \%$ agarose gel (Figure $6 \mathrm{C}$ ).

A
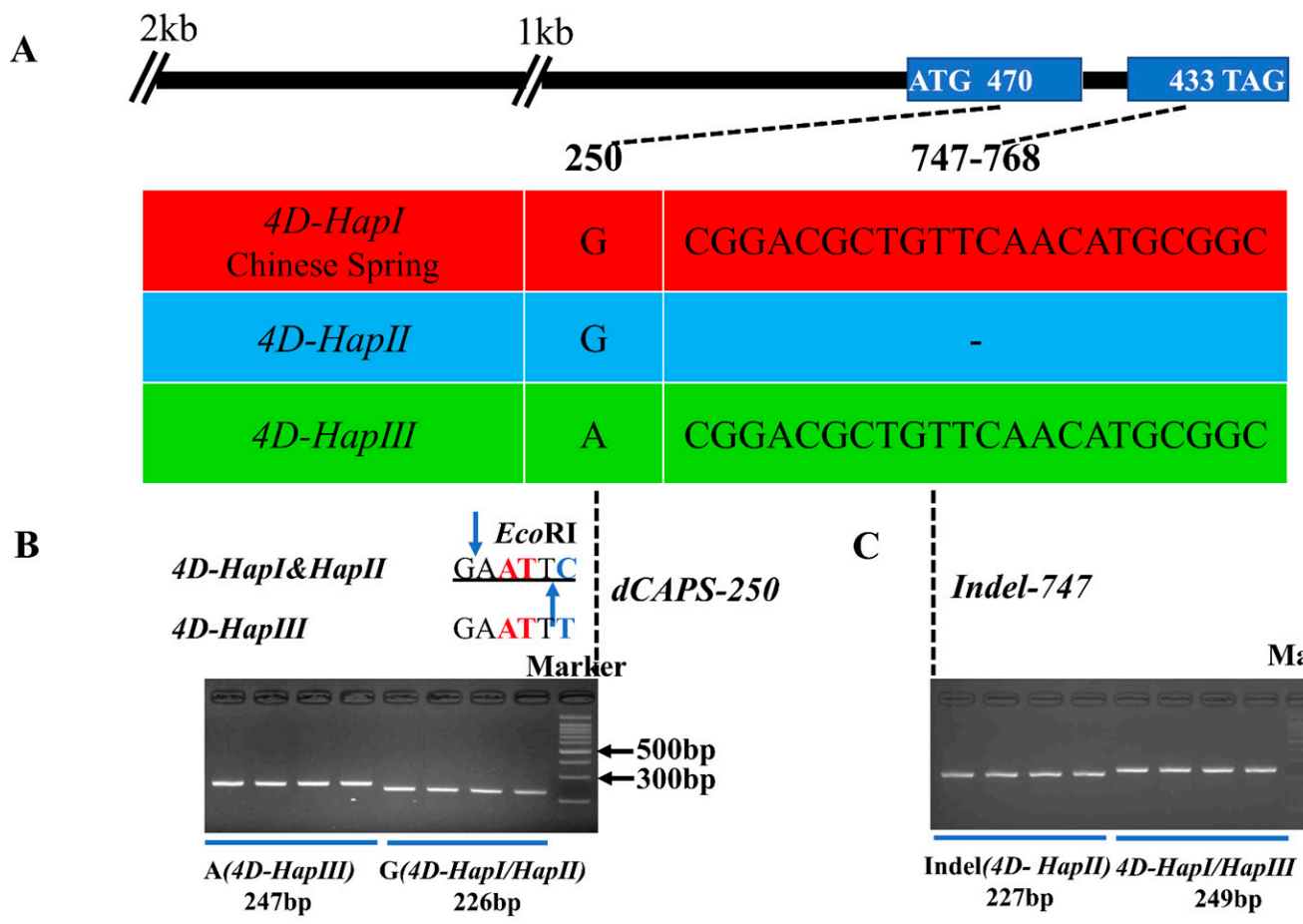
The association between haplotypes and agronomic traits was analyzed in a mini-core collection (MCC) of 262 wheat accessions [47]. After scanning 262 MCC members by the two molecular markers $d C A P S-250$ and Indel-747, we associated the three haplotypes with 11 agronomic traits collected from MCC members grown under various environments in different years. According to the results, TaD14-4D haplotypes were significantly correlated with effective tillering number (ETN) (Figure 7A, Table 1). The mean ETN of 4D-HapII was significantly higher than that of 4 D-HapI/III plants by 1.45-2.56 in 2002, 2.07-2.55 in 2005, 1.89-2.47 in 2006, and 2.14-3.08 in 2010 (Figure 7A, Table 1). Significant differences were also detected in thousand kernel weight (TKW) (Figure 7B). Interestingly, the TKW of 4D-HapII was significantly lower than that of $4 \mathrm{D}$-HapI/III. These results showed that $4 \mathrm{D}$-HapII had phenotypes of ETN and TKW similar to those of a series of SL signal transduction mutants dwarf14 in rice, including $d 14, d 88$ [48], htd2 [49], and $h t d 4$ [50]. Furthermore, accessions with 4D-HapIII had a lower mean ETN and higher TKW (not reaching a significant level), and $4 \mathrm{D}-\mathrm{HapI}$ was an intermediate haplotype. In summary, these results indicate that $4 D$-HapIII was the favorable haplotype.
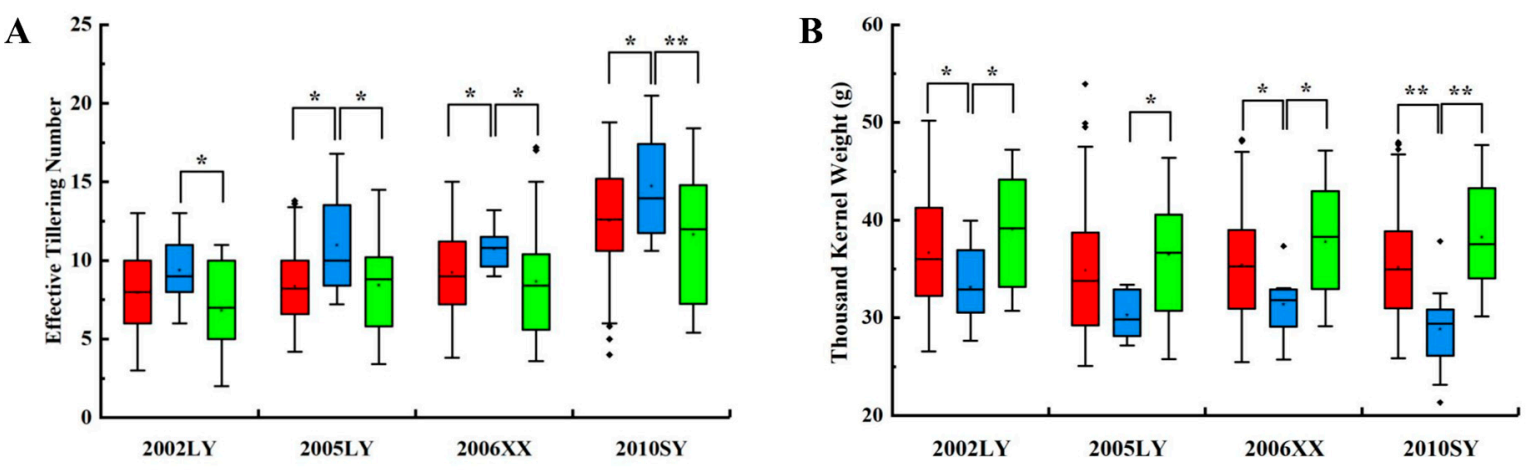

\section{TaD14-4D-HapI $\square$ TaD14-4D-HapII $\square$ TaD14-4D-HapIII}

Figure 7. Association analysis of TaD14-4D haplotypes with effective tillering number and thousand kernel weight in the mini-core collection (MCC). (A,B) Association of TaD14-4D haplotypes with effective tillering number (A) and thousand kernel weight (B) in the mini-core collection (MCC) in four different environments; the $\mathrm{x}$-axis represents different environments (Luoyang, 2002; Luoyang, 2005; Xinxiang, 2006; Shunyi, 2010). The asterisks indicate significant differences between haplotypes (Student's $t$-test, ${ }^{*} p<0.05,{ }^{* *} p<0.01$ ).

Table 1. TaD14-4D haplotypes associated with agronomic traits in MCC in four environments.

\begin{tabular}{|c|c|c|c|c|}
\hline Environment & Haplotype & PH (cm) & ETN & TKW (g) \\
\hline \multirow{3}{*}{ 2002LY } & $4 D-H a p I$ & $108.10 \pm 1.35 \mathrm{a}$ & $7.93 \pm 0.19 \mathrm{ab}$ & $37.54 \pm 0.54 a$ \\
\hline & 4D-HapII & $107.50 \pm 4.67 a$ & $9.38 \pm 0.80 \mathrm{a}$ & $33.14 \pm 1.32 b$ \\
\hline & 4D-НарIII & $107.96 \pm 4.33 a$ & $6.82 \pm 0.71 b$ & $39.07 \pm 1.40 \mathrm{a}$ \\
\hline \multirow{3}{*}{ 2005LY } & 4D-HapI & $103.93 \pm 1.04 a$ & $8.91 \pm 0.21 a$ & $34.86 \pm 0.46 \mathrm{ab}$ \\
\hline & 4D-HapII & $104.18 \pm 5.84 a$ & $10.98 \pm 1.25 b$ & $31.19 \pm 1.19 a$ \\
\hline & 4D-HapIII & $105.72 \pm 3.34 a$ & $8.43 \pm 0.58 \mathrm{a}$ & $36.48 \pm 1.20 \mathrm{~b}$ \\
\hline \multirow{3}{*}{$2006 X X$} & 4D-HapI & $116.35 \pm 1.21 \mathrm{a}$ & $9.24 \pm 0.19 a$ & $36.08 \pm 0.42 a$ \\
\hline & 4D-HapII & $114.90 \pm 6.28 \mathrm{a}$ & $11.13 \pm 0.58 b$ & $32.05 \pm 1.12 b$ \\
\hline & 4D-HapIII & $112.27 \pm 3.68 \mathrm{a}$ & $8.66 \pm 0.72 \mathrm{a}$ & $37.79 \pm 1.28 \mathrm{a}$ \\
\hline \multirow{3}{*}{ 2010SY } & $4 D-H a p I$ & $103.98 \pm 1.10 \mathrm{a}$ & $12.60 \pm 0.24 \mathrm{a}(\mathrm{AB})$ & $35.73 \pm 0.44 \mathrm{~A}$ \\
\hline & 4D-HapII & $102.72 \pm 5.19 a$ & $14.74 \pm 1.14 \mathrm{~b}(\mathrm{~A})$ & $28.85 \pm 1.26 \mathrm{~B}$ \\
\hline & 4D-HapIII & $102.05 \pm 3.01 \mathrm{a}$ & $11.66 \pm 0.84 \mathrm{a}(\mathrm{B})$ & $38.26 \pm 1.36 \mathrm{~A}$ \\
\hline
\end{tabular}

PH, plant height; ETN, effective tiller number; TKW, thousand kernel weight; 2002 LY, Luoyang (2002); 2005 LY, Luoyang (2005); 2006 XX, Xinxiang (2006); 2010 SY, Shunyi (2010). Uppercase letters and lowercase letters indicate extremely significant $(p<0.01)$ and significant differences $(p<0.05)$ between haplotypes, respectively. 


\subsection{Global Distribution of TaD14-4D Haplotypes}

To determine the distributions of different haplotypes of $T a D 14-4 D$ and whether they were selected, 157 landraces from the MCC and 348 cultivars from the modern cultivars (MC) covering 10 different wheat production zones of China were genotyped by the two markers $d C A P S-250$ and Indel-747. From landraces to modern cultivars, the proportions of $4 \mathrm{D}$-HapIII were higher in seven ecological wheat zones, especially in the major production zones (I-IV) and this was consistent with the aforementioned preferred haplotype $4 D$ HapIII (Figure 8A,B). By contrast, the frequency of 4D-HapII declined during the transition from landraces to modern cultivars. These results showed that the $4 D$-HapIII underwent positive selection in the process of wheat breeding in China.

A

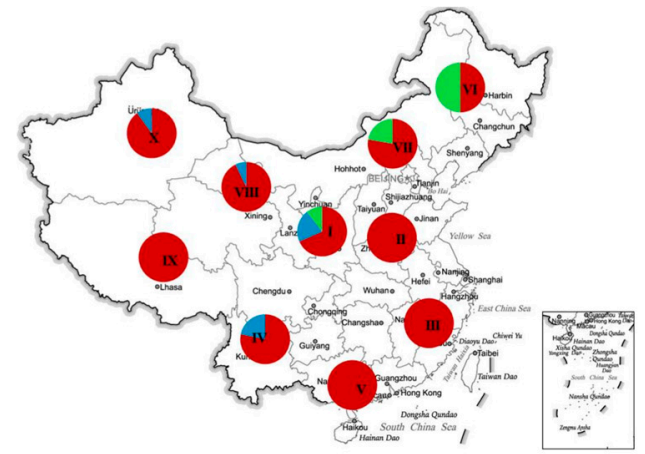

C

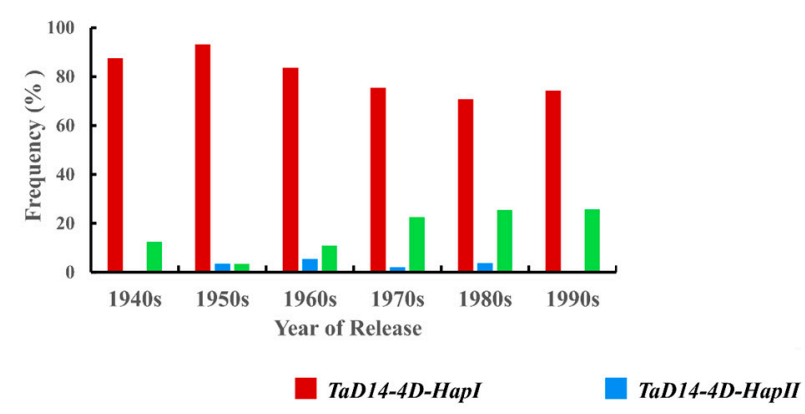

B

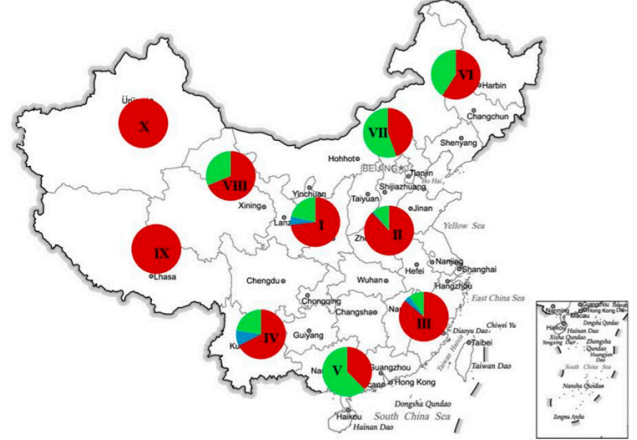

D

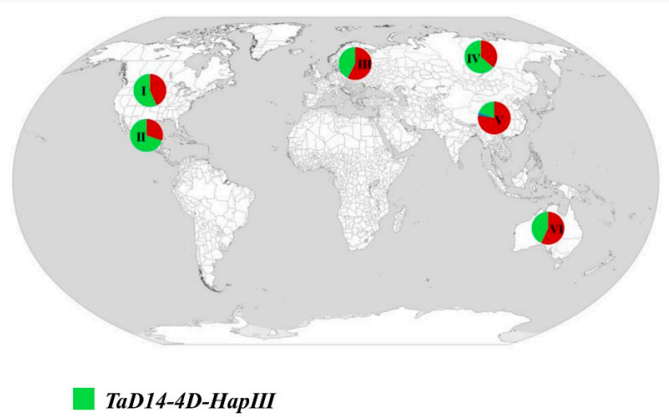

Figure 8. Spatial and temporal distribution of TaD14-4D haplotypes. (A,B) Distribution of TaD14-4D haplotypes in ten Chinese ecological regions (I, northern winter wheat region; II, Yellow and Huai River valley winter wheat region; III, low and middle Yangtze River valley winter wheat region; IV, southwestern winter wheat region; V, southern winter wheat region; VI, northeastern spring wheat region; VII, northern spring wheat region; VIII, northwestern spring wheat region; IX, Qinghai-Tibet spring-winter wheat region; X, Xinjiang winter-spring wheat region). (A) Representation of 157 landraces from ten Chinese ecological regions. (B) Representation of 348 modern cultivars from ten Chinese ecological regions. (C) The changes in the frequency of TaD14-4D haplotypes in Chinese wheat breeding history (from the 1940s to the 2000s). (D) Distribution of TaD14-4D haplotypes in major global wheat ecological regions (I, North America; II, CIMMYT; III, Europe; IV, former USSR; V, China; VI, Australia).

Next, the frequency change of the TaD14-4D haplotypes during Chinese wheat breeding since the 1940s was surveyed. The frequencies of favorable 4 D-HapIII haplotype increased from $12.5 \%$ to $25.7 \%$, but those of 4 D-HapII were gradually eliminated after 1990 (Figure 8C). The proportions of intermediate 4 D-HapI were at a relatively high level, and the favored $4 D$-HapIII had large selection potential.

Finally, we performed genotyping analysis of modern cultivars from Australia, the International Maize and Wheat Improvement Center (CIMMYT), Europe, the former USSR, and North America to assess the global geographic distribution pattern of the TaD14-4D haplotypes (Figure 8D). Similar to the selection trend in China, the proportion of $4 \mathrm{D}$-HapIII was also high in the other five regions, especially in North America, Mexico, and the former USSR. In these regions, the proportion of $4 \mathrm{D}$-HapIII was higher than that of $4 \mathrm{D}$-HapI, 
and the proportion of $4 D$-HapII was very low. These results provide strong evidence that 4 D-HapIII underwent positive selection in global wheat breeding.

\section{Discussion}

\subsection{Functional Conservation of D14 between Wheat and Other Plants}

Strigolactones are a new class of plant hormones. SLs, as carotenoid derivatives, are involved in regulating the growth and development process in a variety of plants [51]. Plant branching is an important agronomic trait that affects plant spatial structure and determines crop yield. Therefore, the study of SL hormones is of great significance to the improvement of plant architecture. The previous studies used forward genetics to screen mutants and confirmed that AtD14 and D14 inhibit plant branching (tillering), and the $d 14$ mutant also showed a dwarfed phenotype [26,48,49]. In rice, a series of D14 allelic mutants had different degrees of decrease in plant height and increase in tillering number, but in general, the degree of change in tillering number was much greater than that of plant height $[26,48,49]$. For example, $h t d 4$ [50] is a mild phenotypic allelic mutant due to the smaller differences in plant height and tillering number compared with the corresponding wild type. In addition, $d 27 / A t d 27$ displayed obviously reduced height and increased tillering (branching) [14,15], but in TaD27-RNAi, tillering was increased yet plant height was not significantly changed [52]. In this study, the TaD14 genes were cloned and identified in common wheat. Through the analysis of the natural variation types of the TaD14-4D, three haplotypes were detected (Figures 4 and 6). The haplotypes were significantly associated with effective tillering number (ETN) but not significantly associated with the plant height (PH) (Figure 7A, Table 1). Although the 4D-HapII haplotype has amino acid changes due to frameshift mutations (Figure 4), we cannot rule out the possibility that mutations are insufficient to affect plant height. This suggests that SL pathway genes may have nuanced functions in wheat.

\subsection{Natural Variation of 4 D-HapII Influences Protein Function}

$D 14$ encodes a member of $\alpha / \beta$-hydrolase superfamily [26]. Studies have shown that D14 is a bifunctional protein functioning as both hydrolase and SL receptor [36]. The crystal structures of DAD2, D14, and AtD14 display that they all have the canonical $\alpha / \beta$-hydrolase domain formed by the substrate-binding pocket and the Ser-His-Asp catalytic triad which is necessary for hydrolase activity [27,34]. It is reported that a cap that is crucial is formed by four helices surrounding the entrance to the active site pocket $[34,53,54]$. In our study, a $22 \mathrm{bp}$ Indel was detected in $4 \mathrm{D}$-HapII, which was a rare mutation, and this haplotype was found to be gradually eliminated during the global breeding process (Figures 6A and 8). Regarding this, there are two possible reasons. Firstly, natural mutations in $4 \mathrm{D}$-HapII led to missense mutations, and the hydrolase domain of the protein was destroyed, especially the highly conserved Ser-His-Asp catalytic triad domain (Figures 4 and 6A). Secondly, our results show that the D14 cap structure is formed by $\alpha 4-\alpha 7$, as seen in Figure 4B. In $4 \mathrm{D}-\mathrm{HapII}, \alpha 6$ and $\alpha 7$ cannot form correctly, so we speculate that the cap structure, which is important for D14 to recognize and hydrolyze SLs, cannot function normally. Therefore, SLs cannot be hydrolyzed in 4D-HapII, which may lead to a lack of interaction between D14-MAX2 and D14-D53 (Figure 5).

\subsection{Effective Molecular Markers for Wheat Breeding}

In recent years, the use of molecular markers, as an effective means to link phenotypic with genotypic variations, has become a powerful tool for the analysis of genetic variation in the agronomic sector $[55,56]$. Markers also allow for a more accurate evaluation of genetic resources to identify new and original alleles [44]. Wheat germplasm resources include very rich allelic variations. Thus, designing a functional molecular marker is an important prerequisite for marker-assisted breeding. In this study, we developed two molecular markers, $d C A P S-250$ and Indel-747, to distinguish haplotypes, and they were associated with ETN and TKW (Figures 6 and 7, Table 1). The 4D-HapIII was associated 
with a higher mean TKW, and its proportion was higher in five wheat production regions than in China (Figures 7 and 8D), so the favorable haplotype 4D-HapIII could be useful for further selection in China. Thus, the newly developed molecular markers can be used for marker-assisted selection breeding in wheat.

\section{Materials and Methods}

\subsection{Plant Materials and Growing Conditions}

The correlation analysis of field agronomic traits and haplotypes was conducted by using a population composed of $262 \mathrm{MCC}$ members [47]. Field agronomic traits included heading date (HD), maturity date (MD), panicle length (PL), spikelet number per spike (SN), grain number per spike (GN), plant height (PH), effective tiller number (ETN), thousand kernel weight (TKW), kernel length (KL), kernel width (KW), and kernel thickness (KT) [57]. Another population of 348 Chinese modern cultivars was used to analyze the temporal and spatial distribution of different haplotypes. A population of 157 Chinese landraces from the MCC was adopted to study the geographic distribution of different haplotypes. These two groups were planted at Luoyang in 2002 and 2005, Xinxiang (only MCC) in Henan Province in 2006, and Shunyi in Beijing in 2010 [58].

A population consisting of 348 Chinese cultivars, 490 North American cultivars, 384 European cultivars, 51 Australian cultivars, 83 Russian cultivars, and 53 CIMMYT cultivars [59] was utilized to investigate the global geographic distribution of TaD14-4D haplotypes.

For tissue expression analysis of the TaD14 homoeologous genes, Chinese Spring cultivated under long-day greenhouse conditions $\left(16 \mathrm{~h}\right.$ light $/ 8 \mathrm{~h}$ dark, $22{ }^{\circ} \mathrm{C}$, relative humidity $70 \%$, light intensity $150 \mu \mathrm{mol} \mathrm{m}^{-2} \mathrm{~s}^{-1}$ ) was used. Tissue samples of roots, stems, and leaves were taken at seedling stage, jointing stage, and heading stage, respectively, and grain samples were taken at different times after flowering. Meanwhile, Chinese Spring was used for genomic cloning and cDNA cloning of TaD14 homoeologous genes.

\subsection{Cloning and Characterization of TaD14 Genes}

The CDS sequence of the rice OsD14 (Os03g0203200) gene published in the China Rice Data Center (http:/ / www.ricedata.cn/gene/index.htm (accessed on 3 January 2020)) was used for a BLAST against IWGSC Survey Sequence Assemblies (https: / / urgi.versailles. inra.fr/blast/blast.php (accessed on 3 January 2020)). Three homoeologous gene sequences with high similarity to OsD14 sequence were obtained. According to sequence differences between the three homoeologous genes, specific primers were designed by the Primer Premier 5.0 software and NCBI Primer-BLAST (https:/ / www.ncbi.nlm.nih.gov/tools / primerblast/index.cgi?LINK_LOC=BlastHome (accessed on 5 January 2020)). All primers (Table S1) used in this study were synthesized by the BGI Tech (Shenzhen, China).

The cDNA and genomic DNA of Chinese Spring were used as PCR templates. PCR amplification was performed in a total volume of $10 \mu \mathrm{L}$, including $50 \mathrm{ng}$ templates, $1 \mu \mathrm{L}$ forward and reverse primers $(10 \mu \mathrm{M}), 0.096 \mu \mathrm{L}$ dNTPs $(25 \mathrm{mM}), 2 \mu \mathrm{L} 5 \times$ TransStart FastPfu Buffer, and $0.2 \mu \mathrm{L}(2.5 \mathrm{U} / \mu \mathrm{L})$ TransStart FastPfu DNA Polymerase (TransGen Biotech, Beijing, China). PCR was performed with the following procedure: denaturing at $95{ }^{\circ} \mathrm{C}$ for $3 \mathrm{~min}$; followed by 35 cycles of denaturing at $95^{\circ} \mathrm{C}$ for $45 \mathrm{~s}$, annealing at $55-60{ }^{\circ} \mathrm{C}$ for $45 \mathrm{~s}$, and $72{ }^{\circ} \mathrm{C}$ for extension $(1 \mathrm{~kb} / \mathrm{min})$; with a final extension at $72{ }^{\circ} \mathrm{C}$ for $10 \mathrm{~min}$. The PCR products were separated by electrophoresis in $1.5 \%$ agarose gel. The PCR products were purified by an AxyPrep DNA Gel Extraction Kit (Axygen Biosciences, Hangzhou, China), cloned into $p E A S Y$-Blunt cloning vector (TransGen Biotech, Beijing, China), and then transformed to Trans1-T1 Phage Resistant Chemically Competent Cells (TransGen Biotech, Beijing, China) by the heat shock method.

\subsection{RNA Extraction and Gene Expression Analysis}

Total RNA from different tissues was extracted with an RNAprep Pure Plant Kit (Tiangen, Beijing, China), and the cDNA was synthesized using the FastKing RT Kit (Tiangen, Beijing, China). The quantitative PCR (qRT-PCR) was adopted to analyze TaD14 
gene expression levels with Roche Light Cycler 96 using the SYBR Premix Ex Taq (Takara, Dalian, China), as previously described [57]. The $20 \mu \mathrm{L}$ reaction system of qRT-PCR was composed of $2 \mu \mathrm{L}$ of cDNA, $0.4 \mu \mathrm{L}$ of each primer $(2 \mu \mathrm{M}), 0.4 \mu \mathrm{L}$ of ROX Reference Dye $(50 \times)$, and $10 \mu \mathrm{L}$ of $2 \times$ SYBR Premix Ex Taq (Takara, Dalian, China). The qRT-PCR results were obtained for two biological replications, and similar results were observed. Gene expression was calculated from three technical replicates using the ${ }^{\Delta \Delta C t}$ method with TaActin as the endogenous control.

\subsection{Phylogenetic Analysis}

In order to investigate the evolutionary relationship of TaD14 genes, a BLAST search was performed in the UniProt database (https: / / www.uniprot.org/blast/ (accessed on 24 October 2020)) based on the conserved amino acid sequences of TaD14. According to the comparison results, we downloaded the amino acid sequences of D14 proteins of these species and then constructed a phylogenetic tree of D14s from a complete alignment of 47 D27 protein sequences by the neighbor-joining method with 1000 bootstrap replicates and p-distance substitution model using MEGA 7.0. The numbers and positions of exons and introns of each D14 of these species were determined by the comparison of the CDS sequences and the corresponding genomic DNA sequences via GSDS2.0 (Gene Structure Display Server) website (http:/ / gsds.cbi.pku.edu.cn/ (accessed on 3 November 2020)).

\subsection{Subcellular Localization}

For subcellular localization, we amplified the full-length CDS of TaD14/4D-HapII/ TaMAX2/TaD53 without the termination codon with corresponding primers containing $5^{\prime}$ HindIII and $3^{\prime}$ BamHI sites from cDNA by PCR. Then, the purified PCR products were fused with the green fluorescent protein (GFP) in the pJIT163-GFP vector to construct the recombinant vectors. The procedure to obtain wheat leaf protoplasts was according to Yoo et al. (2007) [60]. Four fusion plasmids and free GFP plasmids were transfected into wheat leaf protoplasts for transient expression. The protoplasts were incubated overnight in the dark at $22{ }^{\circ} \mathrm{C}$, and the green fluorescence signal was observed with a confocal microscope (LSM880; Carl Zeiss, Oberkochen, Germany).

\subsection{Yeast Two-Hybrid Assay (Y2H)}

The coding region of TaD53 was cloned into the Y2H "prey" vector pGADT7, and the coding regions of TaD14-4D and 4D-HapII were cloned into the $\mathrm{Y} 2 \mathrm{H}$ "bait" vector pGBKT7. All constructs were confirmed by sequencing and transformed into the yeast strain $\mathrm{Y} 2 \mathrm{H}$ Gold, and the transformants were grown on SD/Trp/Leu plates for 3 days at $30^{\circ} \mathrm{C}$. Yeast strains transformed by TaD53, TaD14-4D, and 4D-HapII in combination with empty vector pGADT7 and pGBKT7 were used as negative control. The yeast transformants were 10-fold serially diluted and spotted onto the selected medium. The interactions between the two proteins were determined on the control medium LT (SD/Trp/Leu) and selective medium LTHA (SD/Trp/Leu/His/Ade) in the presence or absence of $5 \mu \mathrm{M}$ GR24 [3]. Plates were incubated at $30^{\circ} \mathrm{C}$ for 3 days.

\subsection{Luciferase Complementation Imaging (LCI) and Bimolecular Fluorescence Complementation (BiFC) Assay}

For the LCI assay, the CDSs of TaD14-4D and $4 D-H a p I I$ were cloned into n-LUC vectors and the CDS of TaMAX2 was cloned into c-LUC vector to generate the TaD14-4D-n-LUC, 4D-HapII-nLUC, and TaMAX2-c-LUC constructs.

For the BiFC assay, the CDSs of the TaD14-4D and $4 D-H a p I I$ were fused with Nterminal YFP, and TaMAX2 and TaD53 were fused with C-terminal YFP.

Different combinations of the above recombinant constructs were coinfiltrated into Nicotiana benthamiana leaves by Agrobacterium tumefaciens mediated transformation. The corresponding empty vectors were used as negative controls. The LUC and YFP signals were observed $4872 \mathrm{~h}$ after infiltration by the Night SHADE LB 985 Plant Imaging System 
(Berthold Technologies, Bad Wildbad, Germany) and confocal microscope (LSM880; Carl Zeiss, Oberkochen, Germany).

\subsection{SNP Detection and Molecular Marker Development}

Natural variations in the presence of TaD14 genes were detected in 32 common wheat cultivars (Table S2) with high genetic diversity. The genomic and the promoter sequences of TaD14 genes were amplified from 32 common wheat cultivars by PCR. After sequencing, the sequences were aligned by DNAMAN software to identify polymorphism.

Two molecular markers were developed based on polymorphism sites of TaD14$4 D$. Named $d C A P S-250$ and Indel-747, these markers were used to distinguish the three haplotypes of TaD14-4D. According to the difference in polymorphism, these molecular markers were classified into two types: dCAPS marker and Indel marker. The dCAPS marker was developed by dCAPS Finder 2.0 (http:/ / helix.wustl.edu/dcaps/dcaps.html (accessed on 23 July 2020)). Genotyping was performed by two rounds of PCR and one enzyme digestion. In the first round, the genome- or promoter-specific primer was used to amplify fragments, and the reaction system was the same as gene cloning. Then, the PCR product was diluted 10 times, and $1 \mu \mathrm{L}$ was taken as a template for the second round of PCR with dCAPS primers. The second round of PCR was performed in a volume of

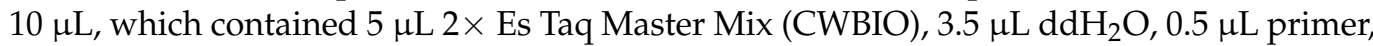
and $1 \mu \mathrm{L}$ template. After the two-step PCR and enzyme digestion, the amplified product containing the restriction enzyme site could be cleaved by the corresponding enzyme. However, the Indel marker required only two rounds of PCR. Finally, the fragments were separated by electrophoresis in $4 \%$ agarose gel.

\subsection{Statistical Analysis}

One-way analysis of variance was performed using IBM SPSS Statistics for Windows version 20.0 (IBM, Armonk, NY, USA) to determine the significance of differences in phenotypic traits among the three haplotypes.

Supplementary Materials: The following are available online at https:/ /www.mdpi.com/article/10.3 390/ijms22073748/s1: Figure S1: Protein structures of TaD14-4A, TaD14-4B and TaD14-4D. Figure S2: Subcellular localization of 4D-HapII, TaMAX2 and TaD53 in wheat leaf protoplasts. Table S1: Primers used in this study. Table S2: The 32 wheat accessions used for polymorphism discovery.

Author Contributions: Conceptualization, X.Z. and Z.Z.; methodology, R.L., H.L., and J.H.; validation, R.L., J.H., H.L., X.Z., Z.Z., and P.X.; formal analysis, R.L., J.H., H.L., X.Z., and Z.Z.; investigation, R.L., J.H., H.L., and X.Z.; resources, X.Z.; data curation, R.L., J.H., X.Z., and Z.Z.; writing-original draft preparation, R.L.; writing-review and editing, R.L., J.H., H.L., X.Z., and Z.Z.; visualization, R.L. and J.H.; supervision, X.Z. and Z.Z.; project administration, X.Z., Z.Z., and P.X.; funding acquisition, X.Z., Z.Z., and P.X. All authors have read and agreed to the published version of the manuscript.

Funding: This research was funded by the National Key Research and Development Program of China (2017YFD0300202-6, 2016YFD0100102, 2016YFD0100605) and the Innovation Academy for Seed Design (Y905023208).

Institutional Review Board Statement: Not applicable.

Informed Consent Statement: Not applicable.

Acknowledgments: We are grateful to Hongliang Zhang, Weiyi Song, Roy Njoroge Kimotho for revising the manuscript.

Conflicts of Interest: The authors declare no conflict of interest. The funders had no role in the design of the study; in the collection, analyses, or interpretation of data; in the writing of the manuscript; or in the decision to publish the results. 


\section{References}

1. Wang, B.; Smith, S.M.; Li, J.Y. Genetic Regulation of Shoot Architecture. Annu. Rev. Plant Biol. 2018, 69, 437-468. [CrossRef] [PubMed]

2. Domagalska, M.A.; Leyser, O. Signal integration in the control of shoot branching. Nat. Rev. Mol. Cell Biol. 2011, 12, 211-221. [CrossRef]

3. Zhou, F.; Lin, Q.B.; Zhu, L.H.; Ren, Y.L.; Zhou, K.N.; Shabek, N.; Wu, F.Q.; Mao, H.B.; Dong, W.; Gan, L.; et al. D14-SCF ${ }^{D 3}$ dependent degradation of D53 regulates strigolactone signalling. Nature 2013, 504, 406-410. [CrossRef]

4. Gomez-Roldan, V.; Fermas, S.; Brewer, P.B.; Puech-Pages, V.; Dun, E.A.; Pillot, J.P.; Letisse, F.; Matusova, R.; Danoun, S.; Portais, J.C.; et al. Strigolactone inhibition of shoot branching. Nature 2008, 455, 189-194. [CrossRef]

5. Umehara, M.; Hanada, A.; Yoshida, S.; Akiyama, K.; Arite, T.; Takeda-Kamiya, N.; Magome, H.; Kamiya, Y.; Shirasu, K.; Yoneyama, K.; et al. Inhibition of shoot branching by new terpenoid plant hormones. Nature 2008, 455, 195-200. [CrossRef]

6. Yamada, Y.; Furusawa, S.; Nagasaka, S.; Shimomura, K.; Yamaguchi, S.; Umehara, M. Strigolactone signaling regulates rice leaf senescence in response to a phosphate deficiency. Planta 2014, 240, 399-408. [CrossRef]

7. Ueda, H.; Kusaba, M. Strigolactone Regulates Leaf Senescence in Concert with Ethylene in Arabidopsis. Plant Physiol. 2015, 169, 138-147. [CrossRef]

8. Agusti, J.; Herold, S.; Schwarz, M.; Sanchez, P.; Ljung, K.; Dun, E.A.; Brewer, P.B.; Beveridge, C.A.; Sieberer, T.; Sehr, E.M.; et al. Strigolactone signaling is required for auxin-dependent stimulation of secondary growth in plants. Proc. Natl. Acad. Sci. USA 2011, 108, 20242-20247. [CrossRef]

9. Marzec, M.; Melzer, M. Regulation of Root Development and Architecture by Strigolactones under Optimal and Nutrient Deficiency Conditions. Int. J. Mol. Sci. 2018, 19, 1887. [CrossRef] [PubMed]

10. Yoneyama, K.; Xie, X.N.; Kim, H.I.; Kisugi, T.; Nomura, T.; Sekimoto, H.; Yokota, T.; Yoneyama, K. How do nitrogen and phosphorus deficiencies affect strigolactone production and exudation? Planta 2012, 235, 1197-1207. [CrossRef] [PubMed]

11. Ha, C.V.; Leyva-Gonzalez, M.A.; Osakabe, Y.; Tran, U.T.; Nishiyama, R.; Watanabe, Y.; Tanaka, M.; Seki, M.; Yamaguchi, S.; Dong, N.V.; et al. Positive regulatory role of strigolactone in plant responses to drought and salt stress. Proc. Natl. Acad. Sci. USA 2014, 111, 851-856. [CrossRef]

12. Bu, Q.Y.; Lv, T.X.; Shen, H.; Luong, P.; Wang, J.; Wang, Z.Y.; Huang, Z.G.; Xiao, L.T.; Engineer, C.; Kim, T.H.; et al. Regulation of Drought Tolerance by the F-box Protein MAX2 in Arabidopsis. Plant Physiol. 2014, 164, 424-439. [CrossRef] [PubMed]

13. Alder, A.; Jamil, M.; Marzorati, M.; Bruno, M.; Vermathen, M.; Bigler, P.; Ghisla, S.; Bouwmeester, H.; Beyer, P.; Al-Babili, S. The Path from $\beta$-Carotene to Carlactone, a Strigolactone-Like Plant Hormone. Science 2012, 335, 1348-1351. [CrossRef]

14. Lin, H.; Wang, R.X.; Qian, Q.; Yan, M.X.; Meng, X.B.; Fu, Z.M.; Yan, C.Y.; Jiang, B.; Su, Z.; Li, J.Y.; et al. DWARF27, an IronContaining Protein required for the Biosynthesis of Strigolactones, Regulates Rice Tiller Bud Outgrowth. Plant Cell 2009, 21, 1512-1525. [CrossRef] [PubMed]

15. Waters, M.T.; Brewer, P.B.; Bussell, J.D.; Smith, S.M.; Beveridge, C.A. The Arabidopsis Ortholog of Rice DWARF27 Acts Upstream of MAX1 in the Control of Plant Development by Strigolactones. Plant Physiol. 2012, 159, 1073-1085. [CrossRef] [PubMed]

16. Booker, J.; Auldridge, M.; Wills, S.; McCarty, D.; Klee, H.; Leyser, O. MAX3/CCD7 Is a Carotenoid Cleavage Dioxygenase Required for the Synthesis of a Novel Plant Signaling Molecule. Curr. Biol. 2004, 14, 1232-1238. [CrossRef] [PubMed]

17. Zou, J.H.; Zhang, S.Y.; Zhang, W.P.; Li, G.; Chen, Z.X.; Zhai, W.X.; Zhao, X.F.; Pan, X.B.; Xie, Q.; Zhu, L.H. The rice HIGHTILLERING DWARF1 encoding an ortholog of Arabidopsis MAX3 is required for negative regulation of the outgrowth of axillary buds. Plant J. 2006, 48, 687-698. [CrossRef]

18. Wang, Y.X.; Shang, L.G.; Yu, H.; Zeng, L.J.; Hu, J.; Ni, S.; Rao, Y.C.; Li, S.F.; Chu, J.F.; Meng, X.B.; et al. A Strigolactone Biosynthesis Gene Contributed to the Green Revolution in Rice. Mol. Plant 2020, 13, 923-932. [CrossRef]

19. Arite, T.; Iwata, H.; Ohshima, K.; Maekawa, M.; Nakajima, M.; Kojima, M.; Sakakibara, H.; Kyozuka, J. DWARF10, an RMS1/MAX4/DAD1 ortholog, controls lateral bud outgrowth in rice. Plant J. 2007, 51, 1019-1029. [CrossRef]

20. Waters, M.T.; Gutjahr, C.; Bennett, T.; Nelson, D.C. Strigolactone Signaling and Evolution. Annu. Rev. Plant Biol. 2017, 68, 291-322. [CrossRef]

21. Seto, Y.; Sado, A.; Asami, K.; Hanada, A.; Umehara, M.; Akiyama, K.; Yamaguchi, S. Carlactone is an endogenous biosynthetic precursor for strigolactones. Proc. Natl. Acad. Sci. USA 2014, 111, 1640-1645. [CrossRef] [PubMed]

22. Zhang, Y.X.; van Dijk, A.D.; Scaffidi, A.; Flematti, G.R.; Hofmann, M.; Charnikhova, T.; Verstappen, F.; Hepworth, J.; van der Krol, S.; Leyser, O.; et al. Rice cytochrome P450 MAX1 homologs catalyse distinct steps in strigolactone biosynthesis. Nat. Chem. Biol. 2014, 10, 1028-1033. [CrossRef] [PubMed]

23. Yoneyama, K.; Mori, N.; Sato, T.; Yoda, A.; Xie, X.N.; Okamoto, M.; Iwanaga, M.; Ohnishi, T.; Nishiwaki, H.; Asami, T.; et al Conversion of carlactone to carlactonoic acid is a conserved function of MAX1 homologs in strigolactone biosynthesis. New Phytol. 2018, 218, 1522-1533. [CrossRef]

24. Morffy, N.; Faure, L.; Nelson, D.C. Smoke and Hormone Mirrors: Action and Evolution of Karrikin and Strigolactone Signaling. Trends Genet. 2016, 32, 176-188. [CrossRef]

25. Shabek, N.; Ticchiarelli, F.; Mao, H.B.; Hinds, T.R.; Leyser, O.; Zheng, N. Structural plasticity of D3-D14 ubiquitin ligase in strigolactone signalling. Nature 2018, 563, 652-656. [CrossRef]

26. Arite, T.; Umehara, M.; Ishikawa, S.; Hanada, A.; Maekawa, M.; Yamaguchi, S.; Kyozuka, J. d14, a Strigolactone-Insensitive Mutant of Rice, Shows an Accelerated Outgrowth of Tillers. Plant Cell Physiol. 2009, 50, 1416-1424. [CrossRef] [PubMed] 
27. Chevalier, F.; Nieminen, K.; Sanchez-Ferrero, J.C.; Rodriguez, M.L.; Chagoyen, M.; Hardtke, C.S.; Cubas, P. Strigolactone Promotes Degradation of DWARF14, an $\alpha / \beta$ Hydrolase Essential for Strigolactone Signaling in Arabidopsis. Plant Cell 2014, 26, 1134-1150. [CrossRef]

28. Stirnberg, P.; Furner, I.J.; Ottoline Leyser, H.M. MAX2 participates in an SCF complex which acts locally at the node to suppress shoot branching. Plant J. 2007, 50, 80-94. [CrossRef]

29. Nelson, D.C.; Scaffidi, A.; Dun, E.A.; Waters, M.T.; Flematti, G.R.; Dixon, K.W.; Beveridge, C.A.; Ghisalberti, E.L.; Smith, S.M. F-box protein MAX2 has dual roles in karrikin and strigolactone signaling in Arabidopsis thaliana. Proc. Natl. Acad. Sci. USA 2011, 108, 8897-8902. [CrossRef] [PubMed]

30. Zhao, L.H.; Zhou, X.E.; Yi, W.; Wu, Z.S.; Liu, Y.; Kang, Y.Y.; Hou, L.; de Waal, P.W.; Li, S.L.; Jiang, Y.; et al. Destabilization of strigolactone receptor DWARF14 by binding of ligand and E3-ligase signaling effector DWARF3. Cell Res. 2015, 25, 1219-1236. [CrossRef] [PubMed]

31. Jiang, L.; Liu, X.; Xiong, G.S.; Liu, H.H.; Chen, F.L.; Wang, L.; Meng, X.B.; Liu, G.F.; Yu, H.; Yuan, Y.D.; et al. DWARF 53 acts as a repressor of strigolactone signalling in rice. Nature 2013, 504, 401-405. [CrossRef] [PubMed]

32. Wang, L.; Wang, B.; Jiang, L.; Liu, X.; Li, X.L.; Lu, Z.F.; Meng, X.B.; Wang, Y.H.; Smith, S.M.; Li, J.Y. Strigolactone Signaling in Arabidopsis Regulates Shoot Development by Targeting D53-Like SMXL Repressor Proteins for Ubiquitination and Degradation. Plant Cell 2015, 27, 3128-3142. [CrossRef] [PubMed]

33. Nakamura, H.; Xue, Y.L.; Miyakawa, T.; Hou, F.; Qin, H.M.; Fukui, K.; Shi, X.; Ito, E.; Ito, S.; Park, S.H.; et al. Molecular mechanism of strigolactone perception by DWARF14. Nat. Commun. 2013, 4, 2613. [CrossRef]

34. Hamiaux, C.; Drummond, R.S.; Janssen, B.J.; Ledger, S.E.; Cooney, J.M.; Newcomb, R.D.; Snowden, K.C. DAD2 is an $\alpha / \beta$ Hydrolase Likely to Be Involved in the Perception of the Plant Branching Hormone, Strigolactone. Curr. Biol. 2012, 22, $2032-2036$. [CrossRef] [PubMed]

35. Seto, Y.; Yasui, R.; Kameoka, H.; Tamiru, M.; Cao, M.M.; Terauchi, R.; Sakurada, A.; Hirano, R.; Kisugi, T.; Hanada, A.; et al. Strigolactone perception and deactivation by a hydrolase receptor DWARF14. Nat. Commun. 2019, 10, 191. [CrossRef]

36. Yao, R.F.; Ming, Z.H.; Yan, L.M.; Li, S.H.; Wang, F.; Ma, S.; Yu, C.T.; Yang, M.; Chen, L.; Chen, L.H.; et al. DWARF14 is a non-canonical hormone receptor for strigolactone. Nature 2016, 536, 469-473. [CrossRef]

37. International Wheat Genome Sequencing Consortium (IWGSC). A chromosome-based draft sequence of the hexaploid bread wheat (Triticum aestivum) genome. Science 2014, 345, 1251788. [CrossRef]

38. Wang, Z.Q.; Shi, H.R.; Yu, S.F.; Zhou, W.L.; Li, J.; Liu, S.H.; Deng, M.; Ma, J.; Wei, Y.M.; Zheng, Y.L.; et al. Comprehensive transcriptomics, proteomics, and metabolomics analyses of the mechanisms regulating tiller production in low-tillering wheat. Theor. Appl. Genet. 2019, 132, 2181-2193. [CrossRef]

39. Yu, J.P.; Miao, J.L.; Zhang, Z.Y.; Xiong, H.Y.; Zhu, X.Y.; Sun, X.M.; Pan, Y.H.; Liang, Y.T.; Zhang, Q.; Abdul Rehman, R.M.; et al. Alternative splicing of OsLG3b controls grain length and yield in japonica rice. Plant Biotechnol. J. 2018, 16, 1667-1678. [CrossRef]

40. Wang, X.L.; Wang, H.W.; Liu, S.X.; Ferjani, A.; Li, J.S.; Yan, J.B.; Yang, X.H.; Qin, F. Genetic variation in ZmVPP1 contributes to drought tolerance in maize seedlings. Nat. Genet. 2016, 48, 1233-1241. [CrossRef]

41. Liu, H.; Li, H.F.; Hao, C.Y.; Wang, K.; Wang, Y.M.; Qin, L.; An, D.G.; Li, T.; Zhang, X.Y. TaDA1, a conserved negative regulator of kernel size, has an additive effect with TaGW2 in common wheat (Triticum aestivum L.). Plant Biotechnol. J. 2020, 18, 1330-1342. [CrossRef] [PubMed]

42. Wang, Y.M.; Hou, J.; Liu, H.; Li, T.; Wang, K.; Hao, C.Y.; Liu, H.X.; Zhang, X.Y. TaBT1, affecting starch synthesis and thousand kernel weight, underwent strong selection during wheat improvement. J. Exp. Bot. 2019, 70, 1497-1511. [CrossRef] [PubMed]

43. Cao, S.H.; Xu, D.G.; Hanif, M.; Xia, X.C.; He, Z.H. Genetic architecture underpinning yield component traits in wheat. Theor. Appl. Genet. 2020, 133, 1811-1823. [CrossRef] [PubMed]

44. Paux, E.; Sourdille, P.; Mackay, I.; Feuillet, C. Sequence-based marker development in wheat: Advances and applications to breeding. Biotechnol. Adv. 2012, 30, 1071-1088. [CrossRef]

45. International Wheat Genome Sequencing Consortium (IWGSC). Shifting the limits in wheat research and breeding using a fully annotated reference genome. Science 2018, 361.

46. Hu, Q.L.; He, Y.J.; Wang, L.; Liu, S.M.; Meng, X.B.; Liu, G.F.; Jing, Y.H.; Chen, M.J.; Song, X.G.; Jiang, L.; et al. DWARF14, A Receptor Covalently Linked with the Active Form of Strigolactones, Undergoes Strigolactone-Dependent Degradation in Rice. Front. Plant Sci. 2017, 8, 1935. [CrossRef]

47. Hao, C.Y.; Wang, L.F.; Ge, H.M.; Dong, Y.C.; Zhang, X.Y. Genetic Diversity and Linkage Disequilibrium in Chinese Bread Wheat (Triticum aestivum L.) Revealed by SSR Markers. PLoS ONE 2011, 6, e17279. [CrossRef]

48. Gao, Z.Y.; Qian, Q.; Liu, X.H.; Yan, M.X.; Feng, Q.; Dong, G.J.; Liu, J.; Han, B. Dwarf 88, a novel putative esterase gene affecting architecture of rice plant. Plant Mol. Biol. 2009, 71, 265-276. [CrossRef]

49. Liu, W.Z.; Wu, C.; Fu, Y.P.; Hu, G.C.; Si, H.M.; Zhu, L.; Luan, W.J.; He, Z.Q.; Sun, Z.X. Identification and characterization of HTD2: A novel gene negatively regulating tiller bud outgrowth in rice. Planta 2009, 230, 649-658. [CrossRef]

50. Wang, Y.P.; Tang, S.Q.; Chen, H.Z.; Wu, Z.F.; Zhang, H.; Duan, E.C.; Shi, Q.H.; Wu, Z.M. Identification and molecular mapping of indica high-tillering dwarf mutant $h t d 4$, a mild phenotype allelic mutant of D14 in rice (Oryza sativa L.). Plant Biol. 2017, 19, 851-858. [CrossRef]

51. Omoarelojie, L.O.; Kulkarni, M.G.; Finnie, J.F.; Van Staden, J. Strigolactones and their crosstalk with other phytohormones. Ann. Bot. 2019, 124, 749-767. [CrossRef] [PubMed] 
52. Zhao, B.; Wu, T.T.; Ma, S.S.; Jiang, D.J.; Bie, X.M.; Sui, N.; Zhang, X.S.; Wang, F. TaD27-B gene controls the tiller number in hexaploid wheat. Plant Biotechnol. J. 2020, 18, 513-525. [CrossRef] [PubMed]

53. Zhao, L.H.; Zhou, X.E.; Wu, Z.S.; Yi, W.; Xu, Y.; Li, S.L.; Xu, T.H.; Liu, Y.; Chen, R.Z.; Kovach, A.; et al. Crystal structures of two phytohormone signal-transducing $\alpha / \beta$ hydrolases: Karrikin-signaling KAI2 and strigolactone-signaling DWARF14. Cell Res. 2013, 23, 436-439. [CrossRef] [PubMed]

54. Kagiyama, M.; Hirano, Y.; Mori, T.; Kim, S.Y.; Kyozuka, J.; Seto, Y.; Yamaguchi, S.; Hakoshima, T. Structures of D14 and D14L in the strigolactone and karrikin signaling pathways. Genes Cells 2013, 18, 147-160. [CrossRef] [PubMed]

55. Grover, A.; Sharma, P.C. Development and use of molecular markers: Past and present. Crit. Rev. Biotechnol. 2016, 36, 290-302. [CrossRef]

56. Garrido-Cardenas, J.A.; Mesa-Valle, C.; Manzano-Agugliaro, F. Trends in plant research using molecular markers. Planta 2018, 247, 543-557. [CrossRef]

57. Liu, H.; Li, T.; Wang, Y.M.; Zheng, J.; Li, H.F.; Hao, C.Y.; Zhang, X.Y. TaZIM-A1 negatively regulates flowering time in common wheat (Triticum aestivum L.). J. Integr. Plant. Biol. 2019, 61, 359-376. [CrossRef] [PubMed]

58. Liu, Y.C.; Hou, J.; Wang, X.L.; Li, T.; Majeed, U.; Hao, C.Y.; Zhang, X.Y. The NAC transcription factor NAC019-A1 is a negative regulator of starch synthesis in wheat developing endosperm. J. Exp. Bot. 2020, 71, 5794-5807. [CrossRef]

59. Hou, J.; Li, T.; Wang, Y.M.; Hao, C.Y.; Liu, H.X.; Zhang, X.Y. ADP-glucose pyrophosphorylase genes, associated with kernel weight, underwent selection during wheat domestication and breeding. Plant Biotechnol. J. 2017, 15, 1533-1543. [CrossRef]

60. Yoo, S.D.; Cho, Y.H.; Sheen, J. Arabidopsis mesophyll protoplasts: A versatile cell system for transient gene expression analysis. Nat. Protoc. 2007, 2, 1565-1572. [CrossRef] [PubMed] 